\title{
Random forest age estimation model based on length of left hand bone for asian population
}

\author{
Mohd Faaizie Darmawan ${ }^{1}$, Ahmad Firdaus Zainal Abidin ${ }^{2}$, Shahreen Kasim ${ }^{3}$, \\ Tole Sutikno ${ }^{4}$, Rahmat Budiarto ${ }^{5}$ \\ ${ }^{1,2}$ Soft Computing and Intelligent System (SPINT), Faculty of Computer Systems \& Software Engineering, \\ Universiti Malaysia Pahang, Kuantan, Pahang, Malaysia \\ ${ }^{3}$ Faculty of Computer Science and Information Technology, Universiti Tun Hussein Onn Malaysia, \\ Parit Raja, Johor, Malaysia \\ ${ }^{4}$ Faculty of Industrial Technology, Universitas Ahmad Dahlan, Yogyakarta, Indonesia \\ ${ }^{5}$ College of Computer and Information Technology, Albaha University, Albaha, Saudi Arabia
}

\section{Article Info}

\section{Article history:}

Received Apr 9, 2019

Revised Aug 19, 2019

Accepted Sep 11, 2019

\section{Keywords:}

Age estimation

Computational intelligence

Forensic anthropology

Fuzzy logic

Hand bone

\begin{abstract}
In forensic anthropology, age estimation is used to ease the process of identifying the age of a living being or the body of a deceased person. Nonetheless, the specialty of the estimation models is solely suitable to a specific people. Commonly, the models are inter and intra-observer variability as the qualitative set of data is being used which results the estimation of age to rely on forensic experts. This study proposes an age estimation model by using length of bone in left hand of Asian subjects range from newborn up to 18-year-old. One soft computing model, which is Random Forest (RF) is used to develop the estimation model and the results are compared with Artificial Neural Network (ANN) and Support Vector Machine (SVM), developed in the previous case studies. The performance measurement used in this study and the previous case study are R-square and Mean Square Error (MSE) value. Based on the results produced, the RF model shows comparable results with the ANN and SVM model. For male subjects, the performance of the RF model is better than ANN, however less ideal than SVM model. As for female subjects, the RF model overperfoms both ANN and SVM model. Overall, the RF model is the most suitable model in estimating age for female subjects compared to ANN and SVM model, however for male subjects, RF model is the second best model compared to the both models. Yet, the application of this model is restricted only to experimental purpose or forensic practice.
\end{abstract}

Copyright $@ 2020$ Institute of Advanced Engineering and Science. All rights reserved.

\section{Corresponding Author:}

Mohd Faaizie Darmawan,

Soft Computing and Intelligent System (SPINT),

Faculty of Computer Systems and Software Engineering,

Universiti Malaysia Pahang,

Lebuhraya Tun Razak, Gambang, 26300, Kuantan, Pahang, Malaysia.

Email: faaizie@ump.edu.my

\section{INTRODUCTION}

Age estimation serves a vital role in identifying the individual's details due to the increase of human trafficking, asylum seekers, refugee, criminal responsibility, child pornography, and the falsification of age. The traditional age estimation model using left hand bone as input such as Tanner Whitehouse (TW) [1] and Greulich and Pyle (GP) [2], are based on qualitative data which is the observation of bone morphology from a radiograph of left hand by forensic anthropologist. These models have disadvantages in which the models are considerable intra and inter-observer variability where the estimated age definitely relies on the forensic 
expert. Therefore, different experts with different experience levels will most likely produce a greater variety of intra-observer, which is different predicted age will be produced by the different experts. Thus, the accuracy of bone age assessment is very important.

There are several case studies that used measurement of hand bone (quantitative data) as input for age estimation [3-7]. All the case studies have proved that the measurement of the hand bone is able to be utilized as indicator for age estimation. This study chooses the length of hand bone as an alternative parameter for age estimation. On the other hand, Soft computing models such as ANN, SVM and RF are proved reliable to be used on quantitative data especially for prediction, classification and optimization problem [6-13]. Thus, this study adopts and implements the RF model on the length of hand bone data to perform age estimation. In order to evaluate the performance of the proposed model, this work compares the accuracy results from the experiments with existing ANN model and SVM model that used the same dataset introduced in [6].

\section{RESEARCH METHOD}

\subsection{Research materials}

A sum of three hundred and thirty three X-ray scans of Asians' left-hand bones, 166 of them are male and 167 are female, were taken from the online dataset [14]. The ages range between newborn to 18 years old. Age distribution for these subjects is illustrated in Table 1. This online dataset consists of four populations which are Asian, Hispanic, African American and Caucasian and has been used for many case studies such as in [15-18]. The dataset comprises of individuals below 20 years old without any record of bone problem or bone disease, for instance fractures, osteoarthritis, rheumatoid arthritis, bone cancer or other problems associated with genetic. Due to the fact that bones with such problems have higher tendency to be weak, bristled, misshaped and broken easily that could lead to inaccurate measurements, those bones were excluded in the study. The source of these x-ray scans was from Children's Hospital Los Angeles together with demographic data of patients and reading by radiologists, assigned into 19 groups (new-born, 1 to 18 years old) for both male and female. The details of each subject; the image name, the race, the gender, the chronological age, the date of birth (DOB), the exam date, the height $(\mathrm{cm})$, the weight $(\mathrm{kg})$, the trunk $(\mathrm{cm})$, the reading 1 , and the reading 2 , were perfectly documented for reference and validation purpose. For the record, several previous case studies also have used this dataset to develop age estimation model $[6,7,17,18]$.

Table 1. Six age' groups with its particular subject's age distribution

\begin{tabular}{cccccccc}
\hline Age' group (year) & $16-18$ & $4-6$ & $13-15$ & $7-9$ & $4-6$ & Newborn - 3 & Total \\
\hline Female & 16 & 19 & 23 & 41 & 38 & 30 & 167 \\
Male & 17 & 20 & 18 & 44 & 37 & 30 & 166 \\
\hline
\end{tabular}

According to the structure of a hand bone, it is categorized into four parts, to be specific, proximal phalanx, the distal phalanx, metacarpal and middle phalanx. Three out of four groups consist of five bones each while another group, middle phalanx group has four bones. Therefore, the sum of bones found in a hand is 19. Throughout childhood and adolescence phases, the left hand's bone development can be partitioned into six important stages. The first stage would be the infancy (newborn to 10 months for female, newborn to 14 months for male), followed by the second stage which is the toddler (10 months to 2 years for female, 14 months to 3 years for male), and the third stage which is pre-puberty (2-7 years for female, 3-9 years for male), and the fourth stage which is the early and mid-puberty (7-13 years for female, 9-14 years for male), then the fifth stage which is the late puberty (13-15 years for female, 14-16 years for male) and, lastly the sixth stage which is the post-puberty (15-17 years for female, 16-19 years for male).

To gauge every length of bone in each stage, software of photo manager was utilized to quantify all the nineteen bones by making a line in each bone, beginning from the base-center point to the end-center point of the bone on every X-ray image, and it consequently created the length of the line in centimetre $(\mathrm{cm})$. The line was made by disregarding the epiphyseal (if it happened) in the bone for infancy stage. The lines were made for other phrases by incorporating the epiphyseal regardless of just a small epiphyseal illustrated in the pictures. Figure 1 demonstrates a case of measuring the length of the bone which belongs to a male subject for each stage from his X-ray image with the help of the software. For experiment and analysis purposes, every single measured data from the images was then organized in a spread sheet. 


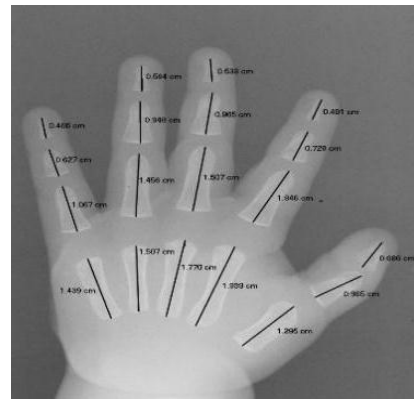

Infancy

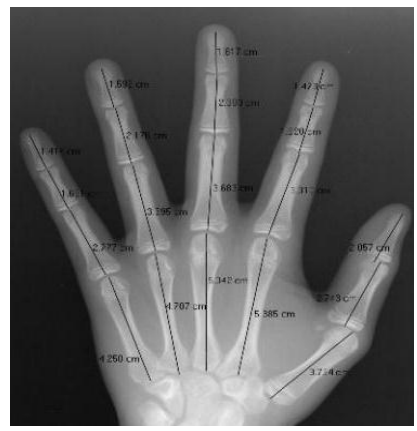

Early and Mid-puberty

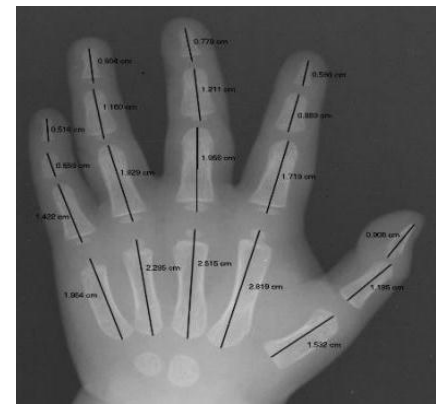

Toddlers

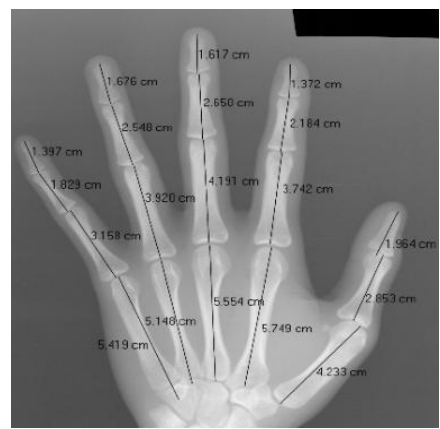

Late Puberty

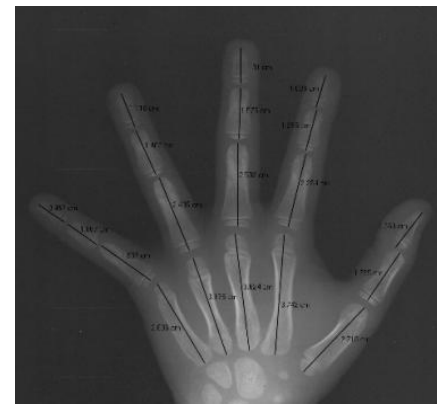

Pre-puberty

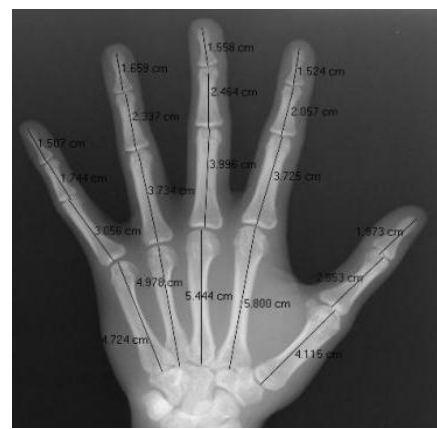

Post-puberty

Figure 1. The created lines with its particular measurement in centimeter, for every bone in the left hand for each phase of bone development

Before the proposed model developed, the normalization of data need to be done. The details of the data normalization are described in the next section. Data normalization is frequently conducted prior to the process of testing and training starts. It is feasible to standardize the input and output to a standard range, for example, -1 to 1 or 0 to 1 . Fundamentally, while nonlinear transfer functions, for instance, the logistic sigmoid function are utilized at the output nodes, the desired output values need to be changed into the scope of the initial output of the system. Regardless of the possibility that a linear output transfer function is utilized, it is yet beneficial to normalize the outputs and additionally the inputs to prevent computational issues. To standardize the gathered length of the bone, the normalization equation from previous studies $[19,20]$ was used which is illustrated in Equation 1 , where $d_{i}$ refers to the ith input/output data, $d_{\text {min }}$ refers to the minimum value of the input/output data and $d_{\max }$ refers to the maximum value of the input/ output data.

$$
x_{i}=\frac{0.8}{d_{\max }-d_{\min }}\left(d_{i}-d_{\min }\right)+0.1
$$

Table 2 illustrates an instance of the measured data gathered from the late puberty $\mathrm{x}$-ray scans in Figure 1 after normalization. In this study, the sum total of X-ray scans for both male and female is 333, it means each X-ray scan has 333 distinctive tables, like the one appeared in Table 2. Small data sets are insufficient for investigations. To overcome this circumstance, it comes to the use of $\mathrm{k}$-fold cross-validation algorithm on RF model. The use of this algorithm aims to separate the entire experiments into two sections which are the training and testing sets. The previous one is utilized to construct the model whereas the latter is to validate the model. The two parts need to traverse in progressive iterations. Ten similarly (roughly) sized sets were divided from the entire sample information in each group, in which every group confirmed a few impact places in every division. For every iteration, only one set was selected for testing whereas the rest were chosen for training. The MSE values were delivered from the testing data in each iteration, and the average of MSE was then figured as the performance for each of the soft computing model. The MSEs from each model were then presented in a table for summarization. After that, comparison was made to determine the best model that can be used for age estimation. The MSE value is chosen because the previous case study that used ANN and SVM also applied MSE as performance function in his work [6]. 
Table 2. Measurement of x-ray image from late puberty phase in Figure 2 after normalization of data

\begin{tabular}{cccccc}
\hline Finger & $1^{\text {st }}$ & $2^{\text {nd }}$ & $3^{\text {rd }}$ & $4^{\text {th }}$ & $5^{\text {th }}$ \\
\hline Metacarpal & 0.8566 & 0.7847 & 0.7512 & 0.7717 & 0.7587 \\
Proximal Phalanx & 0.8364 & 0.8247 & 0.7638 & 0.7859 & 0.8173 \\
Distal Phalanx & 0.8037 & 0.7801 & 0.8399 & 0.8155 & 0.7702 \\
Middle Phalanx & - & 0.8446 & 0.7734 & 0.7130 & 0.7315 \\
\hline
\end{tabular}

\subsection{Random forest}

Random Forest (RF) model is developed by Leo Breiman [21] where the RF has turned into a standard information analysis device in bioinformatics. It has demonstrated outstanding performance in settings where the quantity of observations is much smaller than the number of variables in which complicated interaction structures can be coped well with as well as immensely correlated variables and returns measures of variable importance [22]. RF is a regression and classification model in accordance with the collection of an extensive quantity of decision trees. In particular, it is an aggregation of trees built from a training data set and internally verified to produce a forecast of the reaction provided the predictors for future observations.

The flow of the development of RF model for age estimation is shown in Figure 2. RF model needs selecting parameter $m$, the number of variables (a subset of available $P$ predictor variables) which is utilized to identify the decision at a node of the tree. Several studies [23, 24] have used the square root of the number of input variables to determine the value of $m$, as suggested by Breiman. Breiman also suggested the value of $m$ to be the first integer less than $\log _{2} P+1$, where $P$ is the number of input variables. The optimal value for $m$ can also be identified by the tuneRF function of the R-software. R-software is a free software that offers a wide assortment of statistical linear and nonlinear modelling, classification, time-series analysis, clustering, graphical techniques and classical statistical tests, and is very extendable. TuneRF function starts with the default value of $m$, and then searches for the optimal value (with respect to out-of-bag error estimate) of $m$ for RF model. In this study, the $m$ value was chosen using the three methods above.

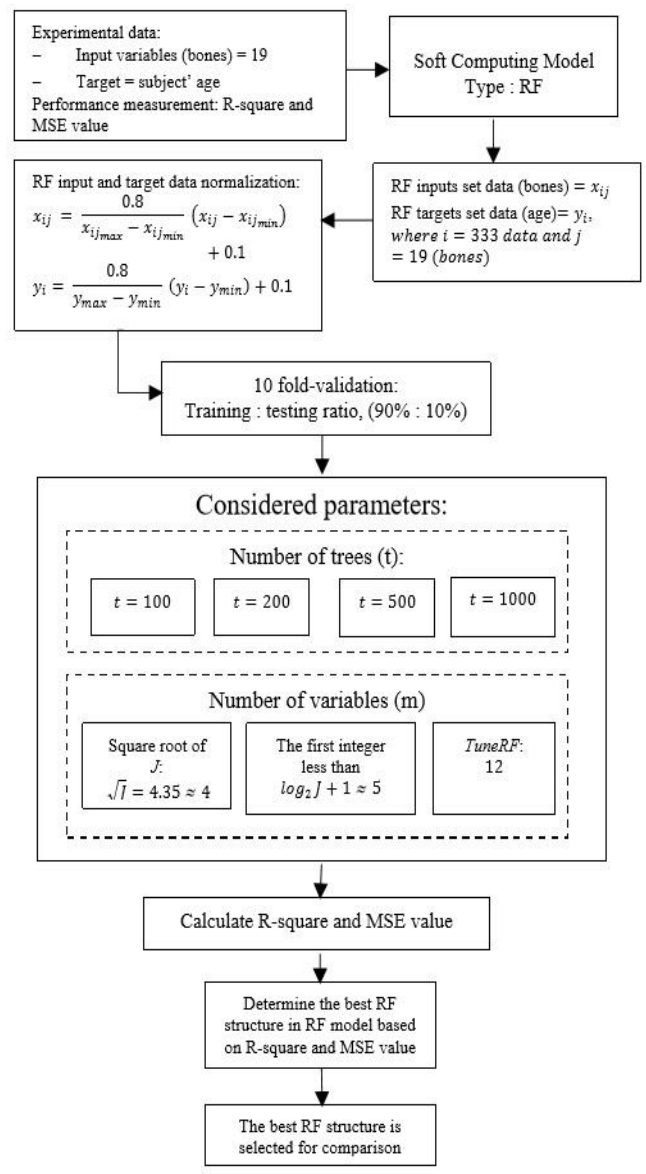

Figure 2. The development of RF model 
The second parameter required by RF is the number of trees, $t$. This study uses four values for $t$, which are 100, 200, 500, and 1000. The combination of these parameters will develop RF's structure used to estimate age. So, the combinations of the parameters used will produce twelve RF's structure which is shown in Table 3. Then, each RF's structure will produce R-square value and MSE value for both male and female. All these values also are shown in the same table. The best RF's structures according to the R-square and MSE values were then selected by comparing each RF's structure and then compiled into Table 4 for comparison purpose with the ANN and SVM produced by the previous case study in [6].

Table 3. R-square and MSE values for different number of trees $(\mathrm{t})$ and number of variables $(\mathrm{m})$ using RF for newborn to 18 years old

\begin{tabular}{cccccc}
\hline Number of trees $(\mathrm{t})$ & Number of Variables $(\mathrm{m})$ & \multicolumn{2}{c}{ Male } & \multicolumn{2}{c}{ Female } \\
& & R-square & MSE & R-square & MSE \\
\hline \multirow{2}{*}{100} & 4 & 0.911 & 2.022 & 0.840 & 3.551 \\
& 5 & 0.911 & 2.027 & 0.842 & 3.524 \\
\multirow{2}{*}{200} & 12 & 0.913 & 1.977 & 0.844 & 3.481 \\
& 4 & 0.914 & 1.958 & 0.843 & 3.497 \\
& 5 & 0.912 & 2.000 & 0.844 & 3.470 \\
500 & 12 & 0.909 & 2.064 & 0.841 & 3.539 \\
& 4 & 0.911 & 2.013 & 0.844 & 3.475 \\
& 5 & 0.912 & 1.995 & 0.842 & 3.507 \\
\multirow{3}{*}{1000} & 12 & 0.911 & 2.027 & 0.843 & 3.498 \\
& 4 & 0.913 & 1.988 & 0.846 & 3.438 \\
& 5 & 0.912 & 2.002 & 0.844 & 3.477 \\
& 12 & 0.912 & 1.994 & 0.845 & 3.455 \\
\hline
\end{tabular}

\section{RESULTS AND ANALYSIS}

Table 3 illustrates the results of age estimation in the form of R-square values and MSE values for both male and female, for each RF's structure. The table reveals that RF's structure with number of tree 200 and number of variable 4 is the best RF's structure which produced the greatest R-square value of 0.914 and lowest MSE value of 1.958 for male, while for female, RF's structure with number of tree 1000 and number of variable 4 is the best structure which produced R-square value of 0.846 and MSE value of 3.438. Figure 3 shows the graph of predicted age produced by RF model and the real age for both genders. The graphs show good relationship between the predicted age and the real age. Table 4 shows the results of the best RF's structure selected before, together with the ANN and SVM's results taken from the previous case study. The table shows that the SVM produced the greatest R-square value of 0.916 and the lowest MSE value of 1.917, for male, while for female, the RF model shows the greatest R-square value of 0.846 and the lowest MSE value of 3.438 .

Table 4. The best R-square and MSE values chosen from the RF model

\begin{tabular}{ccccc} 
and the ANN and SVM model from previous case study \\
\hline Models & \multicolumn{3}{c}{ Male } & \multicolumn{3}{c}{ Female } \\
& R-square & MSE & R-square & MSE \\
\hline ANN [6] & 0.904 & 2.193 & 0.824 & 3.919 \\
SVM [6] & 0.916 & 1.917 & 0.832 & 3.775 \\
RF & 0.914 & 1.958 & 0.846 & 3.438 \\
\hline
\end{tabular}

Forensic anthropologists are ceaselessly endeavouring to enhance the approaches of assessing age through skeletal identification [25]. In a study on sexual dimorphism in carpal bones conducted by Sulzmann et al. [26], the authors claimed that right-hand dominance is a very common occurrence among human populations. Additionally, more prominent practical loading on the dominant hand leads to bigger bone. Therefore, the left hand's bone was utilized in this study since it is relatively less used, which results the growth of these bones to be almost similar among every participants. Participants who are under 19 years old were also investigated in this study. This is because a few research have demonstrated that the methods of age estimation are undependable with an error of more or less twelve years after the 30 years old [27].

For routine forensic application, Rösing and Kvaal [28] expressed that a model that produce standard error of regression of more than 5 or 7 years cannot be accepted for age estimation. $95 \%$ confidence intervals of around 14 years and above need to be taken into account in estimating age, given that there is a standard error of seven years. Selecting the less reliable methods can be troublesome as the estimation of an "apparent age" usually conducted by the investigating teams may not be enhanced by the results, for instance in living human and fresh corpse. Therefore, it will be a waste of money and time. 
There are many reported methods that used bones for age estimation and they are subdivided into three main categories: image processing [29-31], by comparing with bone age atlas [32-34], and statistical regression analysis [35-38]. As being compared with the atlas, as the name proposes, X-ray image of the subjects are being made comparison with an atlas which contains a set of radiographs of identified gender and age. Different bone features are reliably extricated in the image processing method. It is being accounted that this model is fit for accomplishing more solid information for age estimation. In comparison with the other two methods, regression analysis is a well-known decision because of its comparative and simplistic accuracy. The primary purpose is to find out the relationship between one or more independent variables and a dependent variable through the R-square value produced by the models used. The independent variables are also known as explanatory or predictor variables.

Soft computing models such as RF model can be utilized as option model because it provides advantages such as knowledge of internal system variables is not required, factual calculation and simpler solutions for multiple variable problems. Soft computing is a creative approach in developing computationally savvy frameworks. According to Zadeh [39], soft computing is a developing strategy towards computing which corresponds to the important capacity of the human intelligence to comprehend in a domain of imprecision and vulnerability. In this study, measurement was made on a total number of 19 bones in the left hand and RF soft computing models were conducted on all the bones to estimate age. For comparison purpose, for male, the best soft computing age estimation model according to the performance measurement produced is SVM model where the R-square and MSE value produced is 0.916 and 1.917, respectively. For female, RF is the best soft computing model where the R-square and MSE value produced is 8.46 and 3.438 , respectively as compared with the other models.

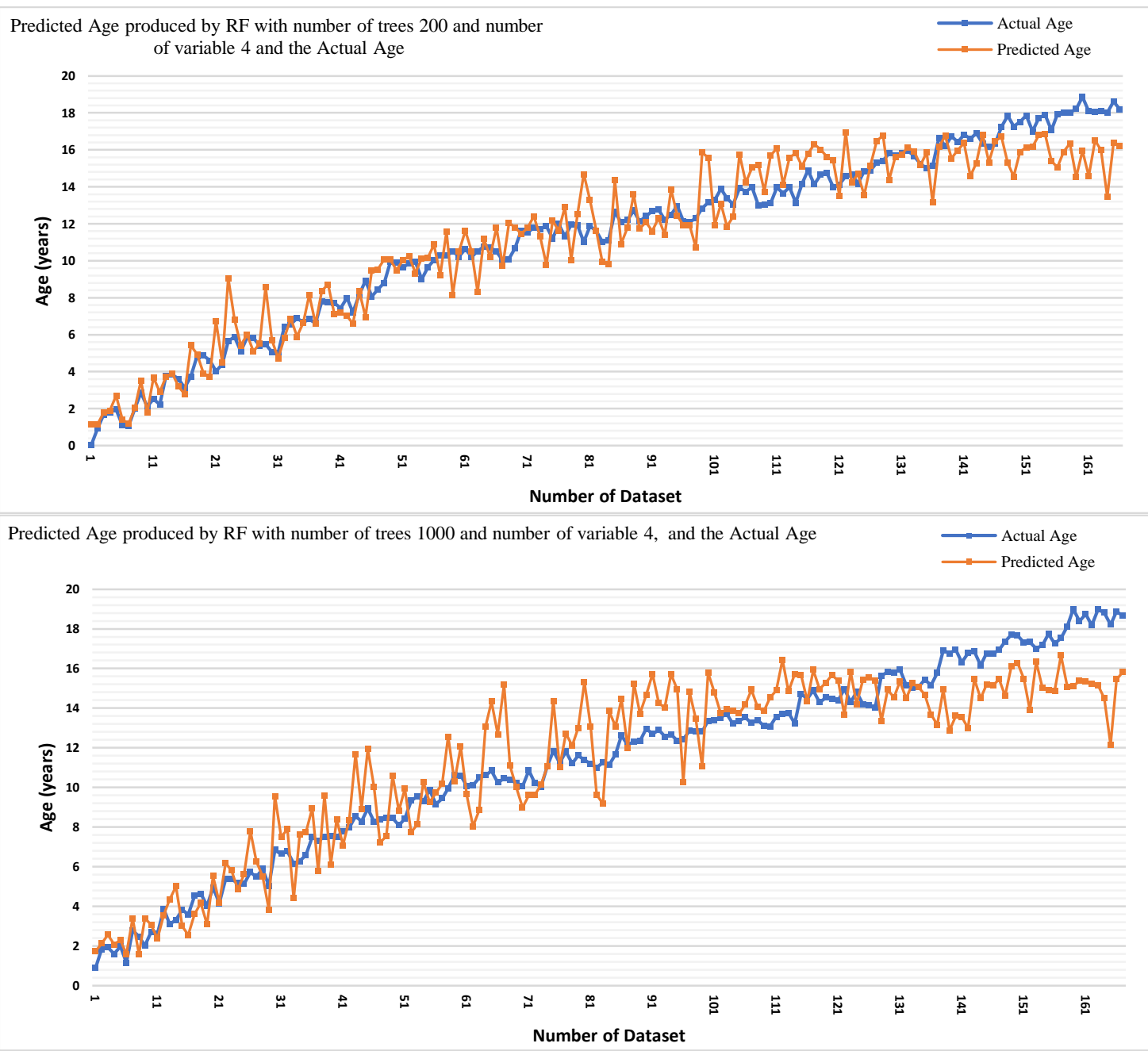

Figure 3. Graph of the predicted age produced by RF model, and the actual age, for both male (the first row) and female (the second row) 
Figure 3 shows the graphs of the predicted output produced by the RF model and the actual age, of both male and female. The graphs show that for male aged from new-born up to 16 years old, the predicted ages of all both models were consistent with the actual age. However, for male above 16 years old, the predicted age seemed to deviate from the actual age, showing inconsistency in output from the both models (see the black line between age 15 years old and 17 years old). For female, the predicted age from the both models showed consistency with the actual age, but after 15 years old, the predicted age also seemed to have deviated from the actual age, same as the male (see the black line between age 14 years old and 16 years old). These findings were similar with the previous case study chosen where the graph produced by ANN and SVM also the show the similar case. Ritz-Timme et al. [40] stated that the validation of age estimation of most morphological methods is the least accurate in adulthood. Santos et al. [41] in their study on age estimation using the Sempé method built for computer - Maturos 4.0 (MT) program showed that the MT program only produced reliable results for age under 16 years old. Molinari et al. [42] in his study also stated that the growth of the skeleton has practically stopped for the skeletal development at the bone age of 16.5 years and 15 years for boys and girls respectively. After that age, the evaluation of age tend to be inaccurate, resulting to a vast deviation between the real and the estimated age. From these supported literatures, we can say that the best range of age for age estimation is between new-born to 16 years old for male, and new-born to 15-16 years old for female. In addition, based on our graphs, our RF model can predict well for both male and female in that range of age.

Generally, different contributing variables such as different methodology approaches, diverse racial backgrounds, or dissimilar environmental conditions, could clarify the contrasts between multiracial investigations of skeletal development [43]. Furthermore, a lot of factors such as nutrition, occupation, endocrine factors, genetic, overall lifestyle and health, growth, and activity significantly influence these indicators in an unforeseeable way $[44,45]$. Due to these reasons, the limitation of technical application need to be done to the targeted population from which the bones were gathered. Estimating age from a particular population should be exceptionally analyzed in which the applied regression models or mathematical functions may differ because of these differences.

\section{CONCLUSION}

According to this study, the number of X-ray of the left hand from a set of data of Asian children were used for age estimation is 333. One soft computing model was used which is RF model to be compared with the ANN and SVM model developed in the previous case study. Based on the findings, RF model is comparable with the ANN and SVM model especially for female where RF model produced better results than ANN and SVM in term of the performance measurement used. However, for male, the RF model is less efficient than SVM model but better than ANN model.

According to the graph produced by the RF model and the supported literature, RF model can estimate well the age for range of age between newborn to 16 years old and between newborn to 15 years old, for male and female, respectively. This finding also proves that the length of bone is reliable to be used as age indicator for age estimation. To conclude, the RF model is still comparable with the other models and suitable to be used for age estimation. However, further study will limit the subject age from new-born to 16 years old for male and new-born to 15 years old for female, for age estimation, according to the supported literatures and the findings. The future study will improve the results of the age estimation by studying other algorithms used by various other case studies available such as by Lenin, Reddy, and Kalavathi [46], Ismail et al. [45], Ismail et al. [46], Khaleel et al. [47] and all other classification methods [48-57].

\section{ACKNOWLEDGEMENTS}

This study thanked to Ministry of Higher Education (MOHE) for Fundamental Research Grant Scheme (FRGS) with grant number RDU190190 and UMP internal grant with grant number RDU1703127, for thier support. 


\section{REFERENCES}

[1] J. M. Tanner, M. J. R. Healy, H. Goldstein, and N. Cameron, "Skeletal Maturity and Prediction of Adult Height (TW3 Method)," 3 edition. Saunders Ltd, 2001.

[2] W. Greulich and S. Pyle, "Radiographic Atlas of Skeletal Development of the Hand and Wrist," Palo Alto, CA: Stanford Univ. Press, 1971.

[3] R. Cameriere, S. De Luca, R. Biagi, M. Cingolani, G. Farronato, and L. Ferrante, "Accuracy of three age estimation methods in children by measurements of developing teeth and carpals and epiphyses of the ulna and radius.," J. Forensic Sci., vol. 57, no. 5, pp. 1263-70, Sep. 2012.

[4] A. a. El-Bakary et al., "Age estimation in Egyptian children by measurements of carpals and epiphyses of the ulna and radius," J. Forensic Radiol. Imaging, vol. 2, no. 3, pp. 121-125, 2014.

[5] M. F. Darmawan, S. M. Yusuf, M. R. Abdul Kadir, and H. Haron, "Age estimation based on bone length using 12 regression models of left hand X-ray images for Asian children below 19 years old," Leg. Med., vol. 17, no. 2, pp. 71-78, 2015.

[6] M. F. Darmawan, M. Z. Osman, and K. Moorthy, "Age Estimation of Asian Using Soft Computing Model Based on Bone Length of Left Hand," Adv. Sci. Lett., vol. 24, no. 10, pp. 7559-7565, 2018.

[7] M. Darmawan, H. Hasan, S. Sadimon, S. Yusuf, and H. Haron, "A Hybrid Artificial Intelligent System for Age Estimation Based on Length of Left Hand Bone,” Adv. Sci. Lett., vol. 24, no. 2, pp. 1047-1051, 2018.

[8] K. Moorthy, M. S. Mohamad, and S. Deris, "Multiple Gene Sets for Cancer Classification Using Gene Range Selection Based on Random Forest," Asian Conf. Intell. Inf. Database Syst., pp. 385-393, 2013.

[9] D. Navega, C. Coelho, R. Vicente, M. T. Ferreira, S. Wasterlain, and E. Cunha, "AncesTrees: ancestry estimation with randomized decision trees," Int. J. Legal Med., vol. 129, no. 5, pp. 1145-1153, 2015.

[10] D. Navega, R. Vicente, D. N. Vieira, A. H. Ross, and E. Cunha, "Sex estimation from the tarsal bones in a Portuguese sample: a machine learning approach,” Int. J. Legal Med., vol. 129, no. 3, pp. 651-659, 2015.

[11] Š. Bejdová, J. Dupej, V. Krajíček, J. Velemínská, and P. Velemínský, "Stability of upper face sexual dimorphism in central European populations (Czech Republic) during the modern age," Int. J. Legal Med., vol. 132, no. 1, pp. 321-330, 2018.

[12] K. Zhang et al., "The role of multislice computed tomography of the costal cartilage in adult age estimation," Int. J. Legal Med., pp. 791-798, 2017.

[13] F. Cavalli, L. Lusnig, and E. Trentin, "Use of pattern recognition and neural networks for non-metric sex diagnosis from lateral shape of calvarium: an innovative model for computer-aided diagnosis in forensic and physical anthropology," Int. J. Legal Med., vol. 131, no. 3, pp. 1-11, 2017.

[14] "https://ipilab.usc.edu/computer-aided-bone-age-assessment-of-children-using-a-digital-hand-atlas-2/."

[15] E. Pietka, A. Gertych, S. Pospiech, F. Cao, H. K. Huang, and V. Gilsanz, "Computer-assisted bone age assessment: Image preprocessing and epiphyseal/metaphyseal ROI extraction,” IEEE Trans. Med. Imaging, vol. 20, no. 8, pp. 715-729, 2001.

[16] H. K. Huang et al., "Data grid for large-scale medical image archive and analysis," in Proceedings of the 13th ACM International Conference on Multimedia, pp. 1005-1013, 2005.

[17] A. Zhang, A. Gertych, B. J. Liu, and H. K. Huang, "Bone Age Assessment for Young Children from Newborn to 7- Year-Old Using Carpal Bones,” Comput. Med. Imaging Graph., vol. 6516, no. 18, pp. 1-11, Mar. 2007.

[18] A. Gertych, A. Zhang, J. Sayre, S. Pospiech-Kurkowska, and H. . Huang, "Bone Age Assessment of Children using a Digital Hand Atlas," Comput Med Imaging Graph, vol. 31, pp. 322-331, 2007.

[19] A. M. Zain, H. Haron, and S. Sharif, "Prediction of surface roughness in the end milling machining using Artificial Neural Network," Expert Syst. Appl., vol. 37, no. 2, pp. 1755-68, Mar. 2010.

[20] M. F. Darmawan, S. M. Yusuf, M. R. Abdul Kadir, and H. Haron, "Comparison on three classification techniques for sex estimation from the bone length of Asian children below 19 years old: An analysis using different group of ages," Forensic Sci. Int., vol. 247, p. 130.e1-130.e11, 2015.

[21] L. Breiman, "Random forests," Mach. Learn., pp. 5-32, 2001.

[22] A. L. Boulesteix, S. Janitza, J. Kruppa, and I. R. König, "Overview of random forest methodology and practical guidance with emphasis on computational biology and bioinformatics," Wiley Interdiscip. Rev. Data Min. Knowl. Discov., vol. 2, no. 129, pp. 493-507, 2012.

[23] P. F. Smith, S. Ganesh, and P. Liu, "A comparison of random forest regression and multiple linear regression for prediction in neuroscience," J. Neurosci. Methods, vol. 220, no. 1, pp. 85-91, 2013.

[24] P. Vezza, R. Muñoz-Mas, F. Martinez-Capel, and a. Mouton, "Random forests to evaluate biotic interactions in fish distribution models," Environ. Model. Softw., vol. 67, pp. 173-183, 2015.

[25] M. Steyn and M. Y. Işcan, "Metric sex determination from the pelvis in modern Greeks.," Forensic Sci. Int., vol. 179, no. 1, p. 86.e1-6, Jul. 2008.

[26] C. E. Sulzmann, J. L. Buckberry, and R. F. Pastor, "The Utility of Carpals for Sex Assessment: A Preliminary Study," Am. J. Phys. Anthropol., vol. 135, pp. 252-262, 2008.

[27] J. M. Suchey, "Problems in the aging of females using the Os pubis," Am. J. Phys. Anthropol., vol. 51, pp. 467-470, 1979.

[28] F. W. Rösing and S. I. Kvaal, "Dental Age in Adults - A Review of Estimation Methods," Dent. Anthropol., pp. 443-468, 1998.

[29] S. Kucheryavski, I. Belyaev, and S. Fominykh, "Estimation of age in forensic medicine using multivariate approach to image analysis," Chemom. Intell. Lab. Syst., vol. 97, no. 1, pp. 39-45, May 2009.

[30] O. Ekizoglu et al., "Computed tomography evaluation of the iliac crest apophysis: age estimation in living 
individuals," Int. J. Legal Med., vol. 130, no. 4, pp. 1101-1107, 2016.

[31] T. Lucas and M. Henneberg, "Estimating a child's age from an image using whole body proportions," Int. J. Legal Med., vol. 131, no. 5, pp. 1385-1390, 2017.

[32] A. De Donno, V. Santoro, S. Lubelli, M. Marrone, P. Lozito, and F. Introna, "Age assessment using the Greulich and Pyle method on a heterogeneous sample of 300 Italian healthy and pathologic subjects.," Forensic Sci. Int., vol. 229, no. 1-3, p. 157.e1-6, Jun. 2013.

[33] M. Schaefer, L. Hackman, and J. Gallagher, "Variability in developmental timings of the knee in young American children as assessed through Pyle and Hoerr's radiographic atlas," Int. J. Legal Med., vol. 130, no. 2, pp. 501-509, 2016.

[34] M. Alcina, A. Lucea, M. Salicrú, and D. Turbón, "Reliability of the Greulich and Pyle method for chronological age estimation and age majority prediction in a Spanish sample," Int. J. Legal Med., vol. 132, no. 4, pp. 1139-1149, 2018.

[35] J. E. O’Connor, J. Coyle, C. Bogue, L. D. Spence, and J. Last, "Age prediction formulae from radiographic assessment of skeletal maturation at the knee in an Irish population.," Forensic Sci. Int., vol. 234, p. 188.e1-8, Jan. 2014.

[36] J. Irurita Olivares and I. Alemán Aguilera, "Proposal of new regression formulae for the estimation of age in infant skeletal remains from the metric study of the pars basilaris," Int. J. Legal Med., vol. 131, no. 3, pp. 1-8, 2017.

[37] K. Zhang, X. Dong, F. Fan, and Z. Deng, "Age estimation based on pelvic ossification using regression models from conventional radiography," Int. J. Legal Med., vol. 130, no. 4, pp. 1143-1148, 2016.

[38] A. B. Márquez-Ruiz, L. González-Herrera, and A. Valenzuela, "Usefulness of telomere length in DNA from human teeth for age estimation," Int. J. Legal Med., vol. 132, no. 2, pp. 353-359, 2018.

[39] L. a Zadeh, "Fuzzy logic, neural networks, and soft computing," Fuzzy Syst., vol. 37, pp. 77-84, 1994.

[40] S. Ritz-Timme et al., "Age estimation: the state of the art in relation to the specific demands of forensic practise.," Int. J. Legal Med., vol. 113, no. 3, pp. 129-36, Jan. 2000.

[41] C. Santos, M. Ferreira, F. C. Alves, and E. Cunha, "Comparative study of Greulich and Pyle Atlas and Maturos 4.0 program for age estimation in a Portuguese sample.," Forensic Sci. Int., vol. 212, no. 1-3, p. 276.e1-7, Oct. 2011.

[42] L. Molinari, T. Gasser, and R. Largo, "A comparison of skeletal maturity and growth.," Ann. Hum. Biol., vol. 40, no. 4, pp. 333-40, Jul. 2013.

[43] A. Al-Hadlaq, M. Al-Qarni, A. Al-Kahtani, and A. Al-Obaid, "Comparative study between hand-wrist method and cervical vertebral maturation method for evaluation of skeletal maturity in Saudi boys," Pakistan Oral Dent. J., vol. 27, no. 2, pp. 187-192, 2007.

[44] R. Malina, "Physical activity and training: effects on stature and adolescent growth spurt," Med Sci Sport. Exerc, vol. 26, pp. 759-66, 1994.

[45] E. Bénéfice, D. Garnier, and G. Ndiaye, "High levels of habitual physical activity in west African adolescent girls and relationship to maturation, growth, and nutritional status: results from a 3-year prospective study.," Am. J. Hum. Biol., vol. 13, no. 6, pp. 808-20, 2001.

[46] K. Lenin, B. R. Reddy, and M. S. Kalavathi, "Progressive Particle Swarm Optimization Algorithm for Solving Reactive Power Problem," Int. J. Adv. Intell. Informatics, vol. 1, no. 3, pp. 125-131, 2015.

[47] M. A. Ismail, V. Mezhuyev, K. Moorthy, S. Kasim, and A. O. Ibrahim, "Optimisation of biochemical systems production using hybrid of newton method, differential evolution algorithm and cooperative coevolution algorithm," Indones. J. Electr. Eng. Comput. Sci., vol. 8, no. 1, pp. 27-35, 2017.

[48] M. A. Ismail, V. Mezhuyev, S. Deris, M. S. Mohamad, S. Kasim, and R. Saedudin, "Multi-objective Optimization of Biochemical System Production Using an Improve Newton Competitive Differential Evolution Method," Int. J. Adv. Sci. Eng. Inf. Technol., vol. 7, no. 4-2, pp. 1535-1542, 2017.

[49] M. K. Khaleel, M. A. Ismail, U. Yunan, and S. Kasim, "Review on Intrusion Detection System Based on The Goal of The Detection System," International Journal of Integrated Engineering, vol. 10, no. 6, 2018.

[50] Zunaidi, W. H. A. W., Saedudin, R. R., Shah, Z. A., Kasim, S., Seah, C. S., \& Abdurohman, M. "Performances Analysis of Heart Disease Dataset using Different Data Mining Classifications," International Journal on Advanced Science, Engineering and Information Technology, 8(6), 2677-2682, 2018.

[51] Kusairi, R. M., Moorthy, K., Haron, H., Mohamad, M. S., Napis, S., \& Kasim, S. "An Improved Parallelized mRMR for Gene Subset Selection in Cancer Classification," International Journal on Advanced Science, Engineering and Information Technology, 7(4-2), 1595-1600, 2017.

[52] Nasrudin, N. A., Chan, W. H., Mohamad, M. S., Deris, S., Napis, S., \& Kasim, S. "Pathway-based Analysis with Support Vector Machine (SVM-LASSO) for Gene Selection and Classification," International Journal on Advanced Science, Engineering and Information Technology, 7(4-2), 1609-1614, 2017.

[53] Nawi, N. M., Zaidi, N. M., Hamid, N. A., Rehman, M. Z., Ramli, A. A., \& Kasim, S. "Optimal Parameter Selection Using Three-term Back Propagation Algorithm for Data Classification," International Journal on Advanced Science, Engineering and Information Technology, 7(4-2), 1528-1534, 2017.

[54] Hasri, N. M., Wen, N. H., Howe, C. W., Mohamad, M. S., Deris, S., \& Kasim, S, "Improved support vector machine using multiple SVM-RFE for cancer classification," International Journal on Advanced Science, Engineering and Information Technology, 7(4-2), 1589-1594, 2017.

[55] Nies, H. W., Daud, K. M., Remli, M. A., Mohamad, M. S., Deris, S., Omatu, S., ... \& Sulong, G. "Classification of Colorectal Cancer Using Clustering and Feature Selection Approaches, " In International Conference on Practical Applications of Computational Biology \& Bioinformatics (pp. 58-65). Springer, Cham, June, 2017.

[56] Remli, M. A., Daud, K. M., Nies, H. W., Mohamad, M. S., Deris, S., Omatu, S., ... \& Sulong, G. "K-means clustering with infinite feature selection for classification tasks in gene expression data," In International 
Conference on Practical Applications of Computational Biology \& Bioinformatics (pp. 50-57). Springer, Cham, June , 2017.

[57] Siang, T. C., Soon, T. W., Kasim, S., Mohamad, M. S., Howe, C. W., Deris, S., ... \& Ibrahim, Z. “A review of cancer classification software for gene expression data," International Journal of Bio-Science and BioTechnology, 7(4), 89-108, 2015. 